A N N A L E S Annales de Bretagne et des Pays de l'Ouest

\title{
Lettres d'Émile Souvestre à Édouard Turquety 1826-1852
}

\section{Pascal Burguin}

\section{OpenEdition}

\section{Journals}

Édition électronique

URL : http://journals.openedition.org/abpo/2538

DOI : $10.4000 /$ abpo. 2538

ISBN : 978-2-7535-2236-7

ISSN : 2108-6443

\section{Éditeur}

Presses universitaires de Rennes

Édition imprimée

Date de publication : 31 décembre 2012

Pagination : 158-159

ISBN : 978-2-7535-2234-3

ISSN : 0399-0826

\section{Référence électronique}

Pascal Burguin, «Lettres d'Émile Souvestre à Édouard Turquety 1826-1852 », Annales de Bretagne et des Pays de l'Ouest [En ligne], 119-4 | 2012, mis en ligne le 31 décembre 2012, consulté le 09 juillet 2020. URL : http://journals.openedition.org/abpo/2538

Ce document a été généré automatiquement le 9 juillet 2020

(c) Presses universitaires de Rennes 


\title{
Lettres d'Émile Souvestre à Édouard Turquety 1826-1852
}

\author{
Pascal Burguin
}

\section{RÉFÉRENCE}

Lettres d'Émile Souvestre à Édouard Turquety 1826-1852 (présentées et annotées par David Steel), Rennes, PUR, coll. « Mémoire commune », Rennes, 2012, ISBN 978-2-7535-1743-1, $12 €$.

1 La publication des Lettres d'Émile Souvestre à Édouard Turquety 1826-1852 par les Presses universitaires de Rennes, dans la collection "Mémoire commune », est une initiative heureuse à plus d'un titre. Elle invite à (re)découvrir deux écrivains bretons un peu oubliés aujourd'hui et rappelle l'intérêt des correspondances d'auteurs pour l'historien car, si ces lettres sont d'abord l'expression d'une belle amitié littéraire, elles témoignent aussi de ce renouveau culturel breton né entre Nantes et Rennes, au tournant des années 1830.

2 Ces lettres avaient déjà fait l'objet d'une analyse commentée par Marie-Françoise Bastit-Lesourd dans le numéro 205 des Cahiers de l'Iroise en 2007 ; elles sont ici publiées intégralement, présentées et annotées avec beaucoup de soin par David Steel, de l'université de Lancastre, et accompagnées d'une dizaine d'articles et de poèmes des deux auteurs. Au total, 51 lettres envoyées par É. Souvestre à son ami, dont 8 écrites avec ses deux épouses successives et 5 fragments de la main d'É. Turquety, tous conservés par la veuve de Turquety et déposés au fonds Souvestre de la bibliothèque municipale de Rennes.

3 Cette correspondance est d'abord une affaire d'amitié. Une amitié improbable née en 1826 sur les bancs de la faculté de droit de Rennes entre deux jeunes hommes à la personnalité et au destin très différents. Édouard Turquety (1807-1867), le fils de famille "enkysté dans le cocon familial rennais " jusqu'à son mariage tardif à 45 ans, monarchiste et «catholique avant tout », avocat par nécessité, poète par vocation, et 
Émile Souvestre (1806-1854), le morlaisien orphelin de père à 18 ans, marié à 24 ans, républicain marqué par le saint-simonisme et vaguement déiste, successivement rédacteur de revue, journaliste, éditeur, directeur de collège et professeur, à Nantes, Brest, Mulhouse puis Paris, touche-à-tout littéraire, auteur prolixe d'articles innombrables, de poésies, de contes, de drames, de vaudevilles, d'essais comme Un philosophe sous les toits, best-seller international ou d'œuvres romanesques comme Le Monde tel qu'il sera, l'un des premiers romans d'anticipation du xix ${ }^{e}$ siècle. Une amitié sincère aussi mais qui semble s'étioler au fil des ans, sans jamais se briser cependant, puisque pour la plupart les lettres datent des dix premières années et se raréfient après 1836 lorsque Souvestre s'installe à Paris. Les deux amis s'épanchent et se consolent, se soutiennent et s'encouragent mutuellement, partagent leurs douleurs et leurs deuils, regrettent de ne pas s'écrire plus souvent, s'inquiètent de leur silence, se soucient du bonheur de l'autre, s'aiment et se le disent. L'expression est libre, parfois hâtive, l'orthographe et la syntaxe incertaines, les sentiments mis à nu, «je vous aime » dit Émile à Édouard, qu'il appelle "mon ami chéri ", lui avouant qu'il « accorde son estime à bien peu de personnes, son amitié à un plus petit nombre encore » (p. 77). Échanges pleins de tendresse et de spontanéité, typiquement romantiques en somme!

Mais si l'essentiel de cette correspondance est d'abord personnelle et familiale, l'historien peut y trouver une source de première main pour l'histoire culturelle et, dans une moindre mesure, politique de la Bretagne du deuxième tiers du xix ${ }^{e}$ siècle. Souvestre et Turquety rêvent tous les deux de réussite littéraire. Ils ne sont pas les seuls Bretons, en cette période d'épanouissement du romantisme, à tenter l'aventure parisienne pour recevoir l'onction de leurs aînés, Hugo, Nodier ou Lamartine, puis, après les premières déceptions, à se replier vers Rennes ou Nantes pour participer à la renaissance culturelle de la Bretagne. Ces lettres confirment le rôle joué par le nantais Camille Mellinet (1795-1843) et le rennais Alphonse Marteville (1804-1867) dans ce printemps littéraire breton, comme imprimeurs et éditeurs de revues littéraires, le Lycée armoricain de Mellinet en 1823, repris par La Revue de l'Ouest de Souvestre en 1830 avant disparaître en 1831, ou la Revue de Bretagne de Marteville en 1833 prolongée par la Nouvelle Revue de Bretagne jusqu'en 1841. Ces publications ont pendant plus d'une quinzaine d'années fait connaître tous les auteurs bretons importants de la période: outre nos deux épistoliers, Hippolyte Lucas, Alexandre Duval, Évariste Boulay-Paty, Tristan Corbière, Auguste Brizeux et les poètes rennais du Foyer.

5 En revanche, nul écho des événements politiques de la période, pas même des Trois Glorieuses, dans ces lettres qui permettent néanmoins de reconstituer en partie le réseau de relations personnelles nouées entre Souvestre et ses contacts nantais ou rennais, sur la base d'affinités intellectuelles et politiques. Les républicains saintsimoniens de Nantes sont bien connus, Ange Guépin et René-Marie Luminais, avec qui Souvestre fonde en 1829 la Librairie industrielle à des fins d'éducation populaire. Ceux de Rennes le sont un peu moins, comme les avocats Pierre-Charles Provins, fondateur de l'Association républicaine de l'Ouest en 1833, ou Louis Hamon, futur commissaire de la République en Ille-et-Vilaine en 1848, et l'historien de Rennes, Émile Ducrest de Villeneuve, correspondant de l'École sociétaire fouriériste en Ille-et-Vilaine dans les années 1830-1840, tous enrôlés par Émile Souvestre dans les hommages rendus en 1838 et 1848 à l'ancien maire républicain de Rennes, Joseph Leperdit dont il aurait fallu rectifier, dans l'index, l'orthographe du nom transformé par Souvestre en Perderix ! 
6 L'amitié peut produire des hasards littéraires heureux. Cette correspondance qui intéressera autant les amateurs du genre épistolaire que les chercheurs en est la preuve. 